\title{
Measles-Mumps-Rubella Vaccination in Children with Food Allergy
}

\section{Anju Aggarwal ${ }^{1}$}

Received: 29 July 2019 / Accepted: 29 July 2019 / Published online: 7 August 2019

(C) Dr. K C Chaudhuri Foundation 2019

Measles is caused by a virus belonging to the paramyxovirus family. The transmission is through direct contact and through air. Measles has no animal reservoir and hence, can be eliminated. Measles is a disease associated with both long term and short term complications such as encephalitis, malnutrition, flaring of tuberculosis and subacute sclerosing panencephalitis. About $1,10,000$ people died of measles in 2017, and most of them were children $[1,2]$.

Vaccine for measles is available since 1963. Mumps and rubella are also associated with long term morbidity such as sterility and deafness, and hence, the need for vaccination. To decrease the disease incidence we should have a coverage of more than $80 \%$ of the population. WHO has been planning strategies for measles elimination and a number of countries have been declared measles free including USA in the year 2000. Now there has been a resurgence of measles. Recently, Sri Lanka too has been declared measles free [3] and India has launched MR vaccine campaign for elimination of measles [4].

Only one dose of measles was recommended till 1989 but with early age of acquiring measles disease and incidence of primary vaccine failure, 2 doses as MMR vaccine have been recommended. Recently, MR vaccine campaign has been launched in India to eliminate measles.

Measles vaccine contains strain propagated in chick embryo cell culture and hence may contain trace amount of egg protein. This has been a concern for vaccine reactions in persons with egg or food allergy. Contraindications for MMR vaccination include history of a severe (anaphylactic) reaction to a previous dose or

Anju Aggarwal

aanju67@gmail.com

1 Department of Pediatrics, University College of Medical Sciences and Guru Tegh Bahadur Hospital, New Delhi 110095, India to any component of the vaccine (such as gelatin or neomycin), pregnancy and immunosuppression. MMR may be administered to egg-allergic children without prior routine skin testing as per recommendation by Indian Academy of Pediatrics and American Academy of Pediatrics [1, 5].

In the current issue of the journal, the study by Elitok et al. [6] has been published. The authors retrospectively studied vaccination pattern in children with food or egg allergy; 170 doses of MMR were administered and no serious reaction was observed. The authors observed that physicians in the peripheral institutes were delaying the vaccination and patients were being referred to tertiary care hospitals, thus delaying the age of vaccination and the possibility of the child acquiring the disease. This study reinforces the current recommendation of no prior skin testing and no delay in vaccination in persons with food or egg allergy. Anaphylaxis can develop to any vaccine and hence, facilities should be available for the treatment of anaphylaxis. There is no need for delay or hospitalization for administering the MMR vaccine as seen in other studies from Malasia and Poland [7, 8].

\section{Compliance with Ethical Standards}

Conflict of Interest None.

\section{References}

1. Meissner HC. When should measles vaccine be given? What should be the interval between doses? AAP News. April 19, 2019 Availaeble at: https://www.aappublications.org/news/2019/04/19/ measles041919. Accessed 20 July 2019.

2. World Health Organization. Measles, 19th May 2019. Available at: https://www.who.int/news-room/fact-sheets/detail/measles. Accessed on 20 July 2019.

3. World Health Organization, South East Asia. Sri Lanka eliminates measles. Available at: http://www.searo.who.int/mediacentre/ releases/2019/1712/en/. Accessed 22 July 2019. 
4. World Health Organization, India. Against all odds, India set to make history yet again. Measles-rubella campaign to vaccinate 405 million children by 2019 . Available at: http://www.searo.who.int/india/ topics/measles/MR-campaign-web-success-story/en/. Accessed 22 July 2019.

5. Measles, mumps rubella vaccines. In: Vashistha VM, Choudhary P, Bansal CP, Yewale VN, Agarwal R, editors. IAP Guide Book of Immunization 2013-14. India: IAP National Publication House; 2014. p. 219-34.

6. Elitok GK, Celikboya E, Bulbul L, et al. Does food allergy require any change in measles - mumps -rubella vaccination? Indian J Pediatr. 2019. https://doi.org/10.1007/s12098-019-02981-w.
7. Czajka H, Czajka S, Dylag KA, Boreck E, Kuchar E. Vaccination against measles, mumps, and rubella in the light of current epidemic threats: unjustified postponement. Adv Exp Med Biol. 2019;1153: $101-7$.

8. Tan MS, Teoh EJ, Hor CP, Yeoh AA. Measles- mumps - rubella vaccine for children with egg allergy: is admission for inpatient vaccination necessary? Med J Malaysia. 2016;71:157-60.

Publisher's Note Springer Nature remains neutral with regard to jurisdictional claims in published maps and institutional affiliations. 